\title{
An Instructional Model for Teaching Troubleshooting Skills
}

\author{
Peter Fenrich \\ British Columbia Institute of Technology, Burnaby, Canada \\ peter fenrich@bcit.ca \\ Abstract
}

It is typically difficult or impractical to teach troubleshooting skills in a classroom or lab setting. A computer-based training software package was designed and developed to teach students the problematic skill of how to troubleshoot malfunctions in hydronic heating systems. A summative evaluation was needed to ascertain whether the skills learned on the computer would transfer to the real world. The results of this study show that the instructional model used in teaching learners how to troubleshoot hydronic heating systems was effective $(\mathrm{p}<0.001)$. Learners were able to transfer what they learned on the computer to real systems. Students can effectively learn these troubleshooting skills through CD-ROM delivery without instructor intervention. It is hypothesized that this unique instructional model can be used to teach other troubleshooting skills. This paper describes the initial project and discusses the summative evaluation results.

Keywords: instructional design, computer-based training, multimedia, troubleshooting, CD-ROM

\section{Introduction}

A computer-based training program was needed because traditional teaching methods were not effective in giving learners essential troubleshooting skills. In the field, the workers could follow the schematic diagrams and accurately install hydronic (hot water) heating systems. However, eventually something in the system malfunctioned. Workers were not efficiently repairing malfunctioning systems. As students, they were not taught how to systematically analyze a problem to determine how to fix the system and consequently only replace or repair one component. The problem was that learners were being trained on systems that were fully functional. Instructors were not taking out components, breaking them, and then allowing the learners to go and find out what was not working. If they did it for one learner, the other learners would need to do this independently. If this was done for one component, what about the other 20 components? What about the other 30 types of related systems? This was an excellent problem to solve using instructional technology. The solution was an easy-to-use highly-interactive program that ensured learners could apply the logic needed to troubleshoot both the mechanical and electrical components of hydronic heating systems.

Before the computer-based training program was created an in-depth Internet search was done to see if a software product existed that could teach the troubleshooting skills. Also, companies that were known to create computer-based training materials in the piping field were contacted. The Residential Hot Water Heating Association of British Columbia was also queried as to whether the product existed. All of these

Material published as part of these proceedings, either on-line or in print, is copyrighted by Informing Science. Permission to make digital or paper copy of part or all of these works for personal or classroom use is granted without fee provided that the copies are not made or distributed for profit or commercial advantage AND that copies 1) bear this notice in full and 2) give the full citation on the first page. It is permissible to abstract these works so long as credit is given. To copy in all other cases or to republish or to post on a server or to redistribute to lists requires specific permission from the publisher atpublisher@intormingscience.org sources indicated $t$

Similarly, there was a detailed literature and Internet search to find related instructional models or strategies for teaching troubleshooting skills. Nothing specific was found. Research has only provided general principles for making simulations effective (e.g., Fenrich, 1997 and Thurman, 1993). In general, this program utilizes a discovery learning ap- 
proach (Tuovinen, 2000). A current search also failed to find a relevant instructional model.

The skills that needed to be taught are different from related outcomes such as problem-solving skills. The learners, in the study and those who will use the computer-based training program, do not have to follow a general problem-solving process such as defining the problem (they are told the problem), identifying alternatives (all of the components are potential alternatives), generating possible solutions (they have to consider each component), assessing the solutions (they consider each component based on the data gathered and the "expert" guidance given), and drawing a conclusion (this is done). Consequently, the instructional models of this related field were not helpful.

The feedback provided in the software mimics having an expert beside the learner. However, the program is not an expert system. So, the research related to expert systems was not relevant.

Since the instructional model is unique, proving its effectiveness will enable other instructional designers to use the model for teaching other troubleshooting skills. This will greatly decrease the time they need for the instructional design process and the user-interface and screen design. Also, it will reduce the risk of someone creating an ineffective product.

It is hypothesized that the computer-based training program will significantly increase learning.

\section{Program Description}

The first option on the main menu is the introduction (as shown in Figure 1). The introduction contains pre-requisite information on each hydronic heating system component. This includes what it does, how it works, causes of malfunctions, why service calls are requested, how you can determine if there is a problem, and how you fix the problem. The main menu also provides access to five increasingly complex (e.g., more components such as a secondary pump and mixing valve, radiant panels instead of baseboard panels, and two heating zones instead of one) electrical and mechanical hydronic heating systems.

For each system there is a schematic diagram. Learners are told why a customer has called them (as illustrated in Figure 2). At this point, learners can click on any component in the schematic diagram to see a high-quality photograph of the component and some text details regarding troubleshooting logic. At this point (as shown in Figure 3), learners can choose to see any other component. Alternatively, they can state that the component failed. In this case, the learner will get one of three possible answers. The first likely answer is "Maybe" and it comes with detailed diagnostic feedback that includes information as to what else they would need to know before making a conclusion that the component was defective - as if an expert was beside the learner. This supports a troubleshooting strategy that you should not yet make that conclusion if you do not know some specific pieces of information (e.g., knowing if there is a call for heat, is there heat coming out of the boiler, the pressure, etc.). Learners can now check other components and explore another conclusion. Once learners have the required information, they can get the other two possible answers: a yes or no. Regardless of whether they are right or wrong, they will receive detailed feedback about why they are right or wrong (again as if an expert was guiding them). If they are wrong they can continue by gathering more information to try solving the problem again.

The software also simulates the real world by adding the potential for users to earn $\$ 200$ profit. When a learner states that a component caused the problem and they are wrong, they can only earn a maximum of \$100. Similarly, in the real world, a company would make less money if they replaced a functioning component. After two wrong conclusions learners can only break even and they will lose money with more incorrect component replacements. 


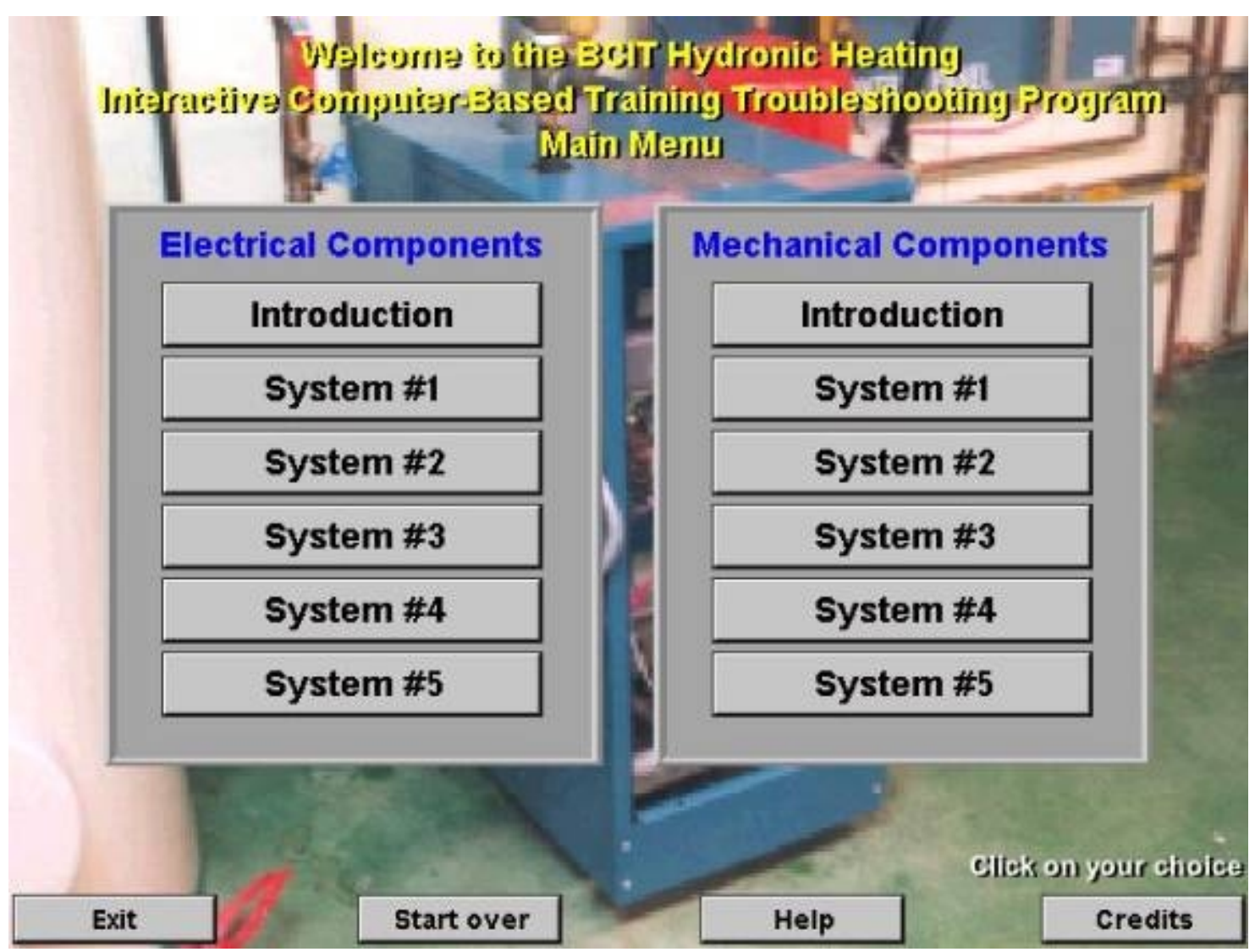

Figure 1 - Main menu

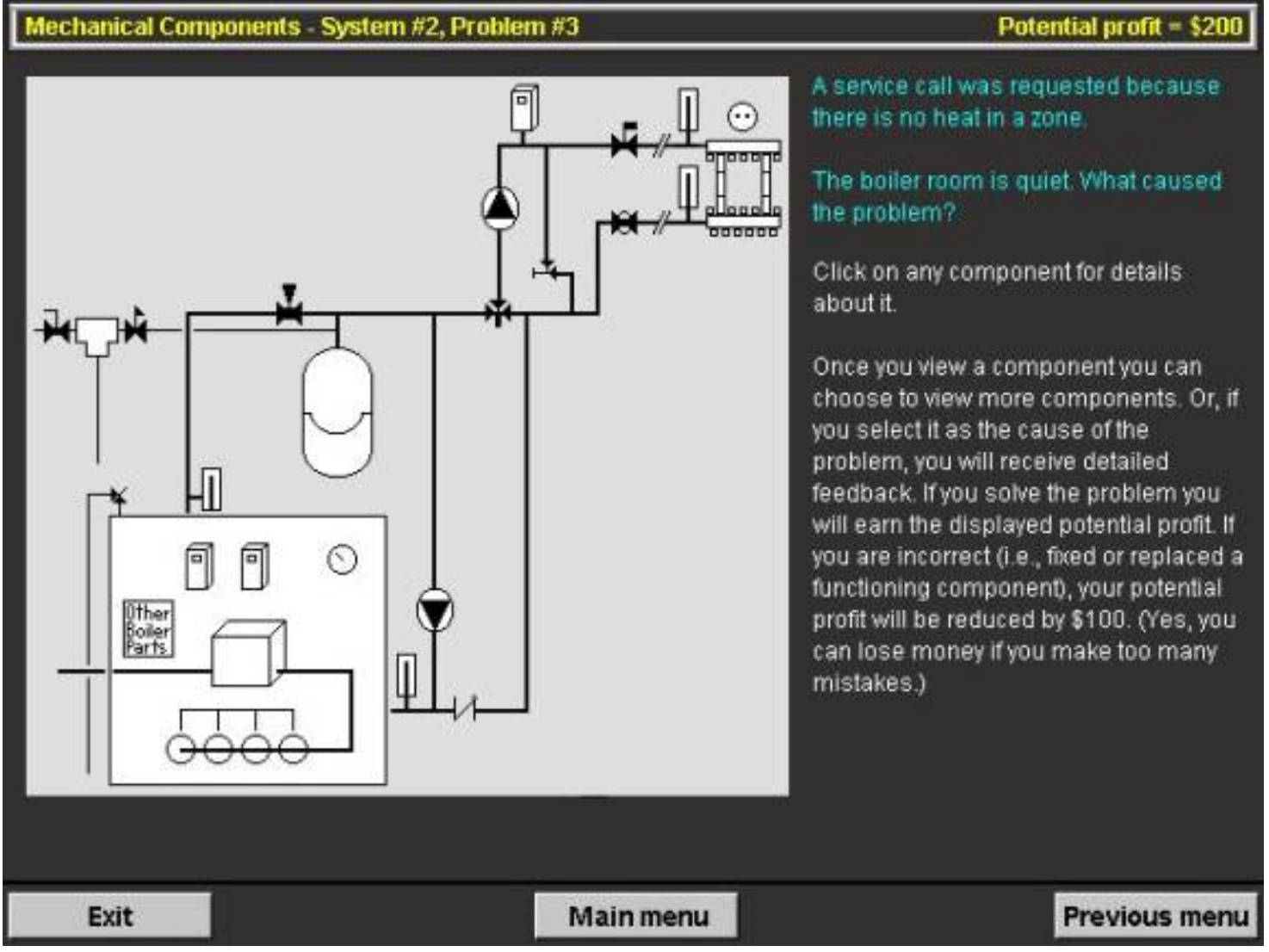

Figure 2 - Schematic of a hydronic heating system 


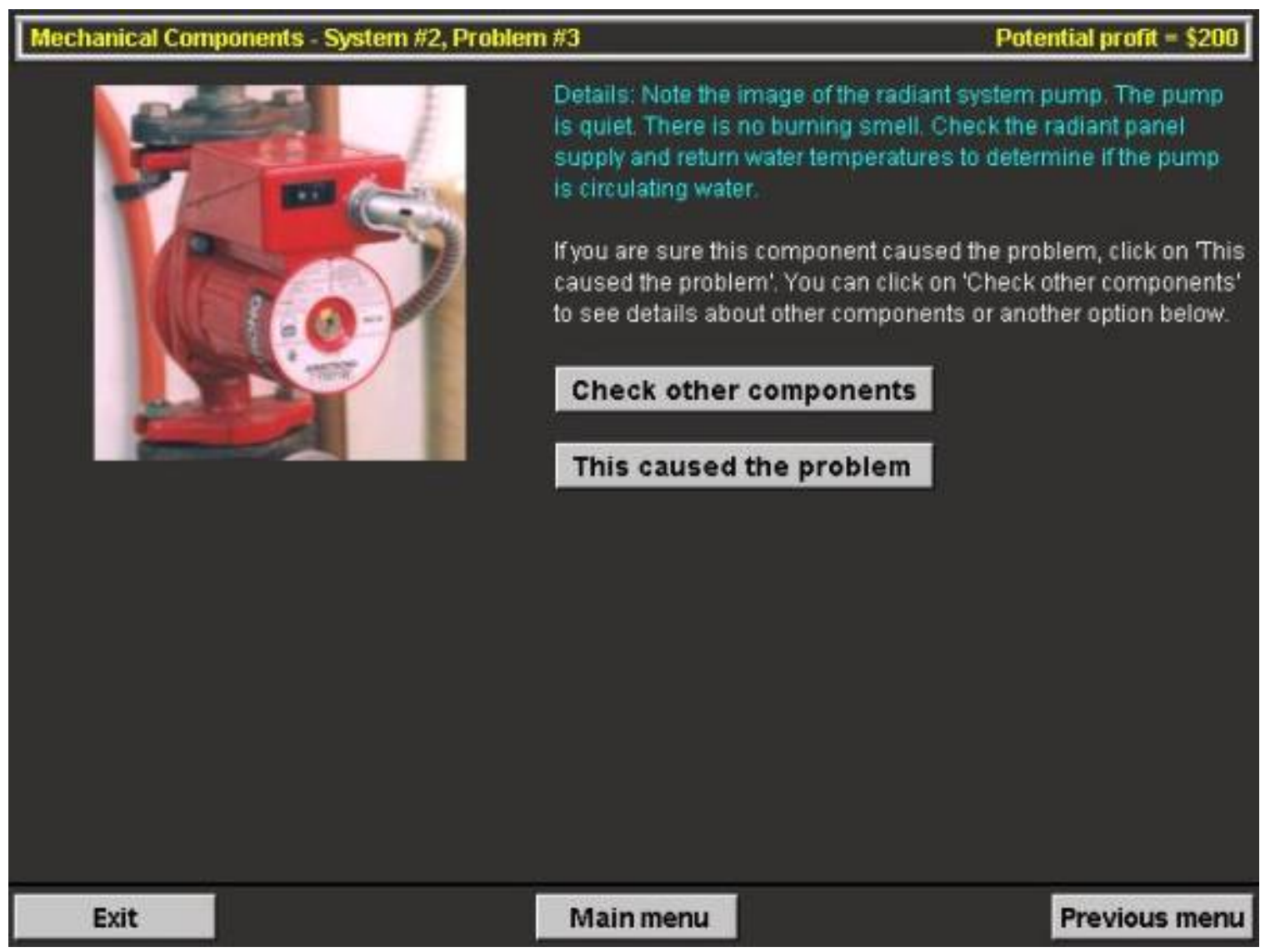

Figure 3 - Learner choices

\section{Methodology}

The participants, three separate groups of second-year "piping trades" students $(\mathrm{N}=36)$, have not been previously taught how to troubleshoot hydronic heating systems. There were 13 participants in the first group, 11 participants in the second group, and 12 participants in the third group. All of the subjects were males. Although, the content of the computer program was related to the field of study of each of the subjects, the content was not required training. Two potential subjects were not included in the study as they felt they were too far behind in their course and lab work to spend time participating in the study. The researcher observed that some subjects seemed to "rush" through the computer program and did not complete every activity.

The evaluation consisted of three steps for each of the three groups: 1) a hands-on pretest in the hydronics lab (all subjects), 2) computer-based training delivered via CD-ROM (randomly assigned to approximately $50 \%$ of the subjects) without instructor intervention, and 3) a hands-on posttest in the hydronics lab (all subjects). Each of the three steps was done on consecutive days in a given week. A two-tailed independent groups t-test was subsequently done to determine if there was a significant difference in pretest scores between those who were taught with the computer-based training software and those who did not receive any training. A two-tailed independent groups t-test was also subsequently done to determine if there was a significant difference in test scores between those who were taught with the computer-based training software and those who did not receive any training.

The pretest and posttest required each participant to try to identify an actual problem in each of four real but different hydronic heating systems. The actual problem was caused by a malfunctioning component. 
For example, malfunctioning components included a pump, zone valve, operating aquastat, and combination gas valve. Recordings were made on the accuracy of conclusions made. In other words, subjects had one try to state which component was faulty in each of the four systems.

\section{Results}

The results of the statistical analysis are summarized in Tables 1 and 2.

\begin{tabular}{lll}
\hline & Training & No Training \\
\hline Mean & 0.32 & 0.33 \\
Variance & 0.079 & 0.029 \\
Observations & 18 & 18 \\
df & 17 & \\
$\mathrm{t}$ value & 0.11 & \\
$\mathrm{P}(\mathrm{T}<=\mathrm{t})$ one-tail & 0.46 & \\
$\mathrm{t}$ Critical one-tail & 1.74 & \\
$\mathrm{P}(\mathrm{T}<=\mathrm{t})$ two-tail & 0.91 & \\
$\mathrm{t}$ Critical two-tail & 2.11 & \\
\hline
\end{tabular}

Table 1. Results of Pretest Scores of Training Versus No Training Subjects

With a two-tailed independent groups t-test, there is no significant difference in pre-test scores between those participants who were taught with the computer-based training software and those who did not receive any training.

\begin{tabular}{lll}
\hline & Training & No Training \\
\hline Mean & 0.5 & 0.16 \\
Variance & 0.26 & 0.13 \\
Observations & 36 & 36 \\
df & 35 & \\
t value & 5.05 & \\
$\mathrm{P}(\mathrm{T}<=\mathrm{t})$ one-tail & 0.000007 & \\
t Critical one-tail & 1.69 & \\
$\mathrm{P}(\mathrm{T}<=\mathrm{t})$ two-tail & 0.000014 & \\
t Critical two-tail & 2.03 & \\
\hline
\end{tabular}

Table 2. Results of Post-test Scores of Training Versus No Training Interventions

With a two-tailed independent groups t-test, there is a significant difference $(M=0.5)$ in test scores between those subjects who were taught with the computer-based training software and those who did not receive any training $(M=0.16, p<0.001)$. Given the participants had to identify the correct malfunctioning component and their question results were recorded as a " 1 " (correct) or "0" (incorrect), standard deviation was not calculated as it would not be an appropriate measure of variance.

\section{Discussion}

The results of this study show that the instructional model used in teaching learners how to troubleshoot hydronic heating systems was effective. Learners were able to transfer what they learned on the computer 
to real systems. Students can effectively learn these troubleshooting skills through CD-ROM delivery without instructor intervention. This is critical as there are many hydronic heating systems installed throughout Canada and workers were not trained in how to troubleshoot malfunctions. Workers can now be effectively trained when and where they want.

A factor that may have impacted the results was that some subjects seemed to "rush" through the computer program. This may be a consequence of some subjects feeling more concerned about their continuing required coursework than participating in the study. If every subject thoroughly completed all of the computer program activities, the test results may have been even more significant (Khoiny, 1995).

It is hypothesized that the same instructional model can be used to effectively teach other troubleshooting skills.

Note that this study did not compare the software program to live teaching. This was not done because training institutions do not explicitly teach this troubleshooting skill (due to the reasons described earlier or because of a lack of equipment).

\section{Acknowledgements}

This summative evaluation was funded through a grant from the Learning Technologies Initiative of the Office of Learning Technologies, Human Resource Development of Canada. This study was supported by the Piping Department of the British Columbia Institute of Technology and the Hot Water Heating Association of British Columbia. The School of Construction and Metal at the British Columbia Institute of Technology funded the original software development. Dr. James Watzke provided invaluable advice on writing this paper.

\section{References}

Fenrich, P. (1997). Practical Guidelines for Creating Instructional Multimedia Applications. Fort Worth, TX: The Dryden Press.

Khoiny, F. (1995). Factors That Contribute to Computer-Assisted Instruction Effectiveness. Computers in Nursing 13(4): 165168.

Thurman, R. (1993). Instructional Simulations from a Cognitive Psychology Viewpoint. Educational Technology Research \& Development 41(4): 75-89.

Tuovinen, J. (2000). Implications of discovery learning research for the design of flexible learning. In Flexible Learning for a Flexible Society, Proceedings of ASET-HERDSA 2000 Conference. Toowoomba, Qld, 2-5 July.

\section{Biography}

Peter Fenrich is a Project Leader/Instructional New Media Designer at the British Columbia Institute of Technology (BCIT). Since 1984, Peter has been designing and developing instructional new media products. His duties include leading projects, writing proposals, designing and developing instructional new media software, conducting research, giving presentations both locally and internationally, training, leading workshops, programming, and evaluating software. His work has been recognized with international awards. Peter also teaches a course, both at BCIT and internationally, that he created entitled "Creating Multimedia Instruction". In 1997, Harcourt Brace published his accompanying textbook to the course. Peter also taught secondary school science and mathematics in Nigeria for two years.

Peter's post-secondary education background includes: a Master of Science in Instructional and Performance Technology, a Professional Certificate in Teaching, a Bachelor of Science, and a Computer Systems Diploma. 